\title{
Turbidite and bottom-current evolution revealed by anisotropy of magnetic susceptibility of redox sediments in the Ulleung Basin, Sea of Japan
}

\author{
GE ShuLan ${ }^{1}$, SHI XueFa ${ }^{1 *}$, LIU YanGuang ${ }^{1}$, WANG KunShan ${ }^{1}$, ZOU JianJun ${ }^{1}$, DIAO JingYu ${ }^{2}$, \\ ZHU ZhiWei ${ }^{1} \&$ WANG ChunJuan ${ }^{1}$
}

${ }^{1}$ First Institute of Oceanography, State Oceanic Administration, Qingdao 266061, China;

${ }^{2}$ Affiliated Middle School of China Ocean University, Qingdao 266003, China

Received May 24, 2011; accepted August 15, 2011; published online November 19, 2011

\begin{abstract}
Anisotropy of magnetic susceptibility (AMS) from above and below $7.31 \mathrm{~m}$ in a core from the southern Ulleung Basin shows clear differences on an equal area projection of the lower hemisphere. Rather concentrated steep inclination of $K_{3}$ and horizontal inclination of $K_{1}$ and $K_{2}\left(K_{1} \geqslant K_{2} \geqslant K_{3}\right)$ are located within the upper part, and the latter two axes lie perpendicular to each other near the bedding plane. In contrast, random distribution of the three axes and extremely high value of shape parameters $\left(Q=\left(K_{1}-K_{2}\right) /\right.$ $\left.\left[\left(K_{1}+K_{2}\right) / 2-K_{3}\right]\right)$ are evident in the lower part, indicating complete destruction of the original sedimentary structure. This result is consistent with data from X-radiographs, which show numerous conglomerates, distortions and cleavages in the lower part. According to age models by Liu et al. (2010) and Zou et al. (2010), the bottom age at $7.31 \mathrm{~m}$ is $48 \mathrm{cal} \mathrm{ka} \mathrm{BP,} \mathrm{and} \mathrm{the} \mathrm{time} \mathrm{domain} \mathrm{is}$ discussed below. The degree of AMS $(P)$ is low, $1-1.08$, and linearly related to the foliation $(F)\left(R^{2}=0.95, N=176\right)$. The relationship between $F$ and linearity $(L)$ implies oblate aligning patterns that are typically sedimentary in origin. At least five redox couplets were found with the aid of $S$ ratios and other rock magnetic parameters, and in most cases, the original signals of climate survived early diagenesis. The paleomagnetically reoriented AMS show corresponding changes with millennial events in the last $48 \mathrm{cal}$ ka. Clearly tilted $K_{3}$ directions and reduction of $P$ and $F$ occurred within DO1-BA warm events, when melt water pulse 1A nd the YD cold event took place. The turbulent conditions therein, synchronous with coarsening of sediments, provide evidence of strong bottom currents and possible directional changes, as evidenced by different $K_{3}$ tilting directions. A NE current direction in the last $4.5 \mathrm{cal} \mathrm{ka}$ is consistent with in situ measurements of bottom currents. Responses of AMS, mainly to climatic modulation, show on the one hand, the limited influence of diagenesis on rock magnetic signals and, on the other hand, the dramatic change of hydrodynamic conditions and terrigenous inputs during rapid sea level rise during the last deglaciation.
\end{abstract}

Ulleung Basin, AMS, susceptibility ellipsoid, early diagenesis

Citation: Ge S L, Shi X F, Liu Y G, et al. Turbidite and bottom-current evolution revealed by anisotropy of magnetic susceptibility of redox sediments in the Ulleung Basin, Sea of Japan. Chin Sci Bull, 2012, 57: 660-672, doi: 10.1007/s11434-011-4812-5

Anisotropy of Magnetic Susceptibility (AMS) is the directional change of magnetic susceptibility of rocks or sediments, and is usually described by parameters of direction and amplitude of three principle axes $\left(K_{1}>K_{2}>K_{3}\right)$ in a magnetic susceptibility ellipse. On a macroscopic scale, AMS reflects the preferred orientation of all materials that are magnetic. At the grain scale, it is determined by the

*Corresponding author (email: xfshi@ fio.org.cn) combination of crystallographic system, iron oxidation state and crystal sites [1]. In sediments laid down by water, AMS is an efficient tool to recognize deformation [2], stress distribution [3] and paleocurrent strength or direction in the deep sea [4,5] or tidal estuaries [6]. AMS also is controlled by climate factors, which correspond to warm and cold cycles [7].

Usually, AMS is only statistically useful in revealing disturbance because of various dynamic conditions, and 
variations in mineral assemblages and granulometry in different marine settings, i.e. there are no absolute criteria for AMS to determine disturbance. For example, although AMS results from the Philippine Sea and Okhotsk Sea are not always "normal", reliable paleointensity is still recorded [8] (and unpublished data from the Okhotsk Sea). After paleomagnetic reorientation [9], AMS can not only indicate disturbance in weakly magnetic sediments from the Sea of Japan, they also reflect millennial environmental changes, without artificial characteristics of shape anisotropy of the cube, sampling, piston core deformation or core splitting [10].

Sediments from the Japan Sea are unusual because slope instability and slumping are common and, in particular, debris flow deposits and turbidites occur in off the southern shelf and slope [11]. In this region, it is possible to recognize gravity slide deposits through AMS. Furthermore, early diagenesis of different degrees is found in high sedimentation rate areas where original magnetites are dissolved and re-precipitated, and redox elements, such as Fe and $\mathrm{Mn}$, are reduced to bivalent and dissolvable phases so that rock magnetic parameters like magnetic susceptibility decrease $[12,13]$. Early diagenesis is very common on continental shelves and slopes where sedimentation rates and organic inputs are so high that organic matter turns sediments anoxic (e.g. [14-18]). High sedimentation rates from 4 to 28 $\mathrm{cm} / \mathrm{ka}$, averaging $15 \mathrm{~cm} / \mathrm{ka}$ [19], and organic carbon from $1 \%-4 \%[20,21]$ in core KCES provide ideal conditions for chemical reduction of the sediments. The color of these sediments ranges from gray-dark to gray, indicating an anoxic state. Frequently occurring gas hydrates can generate methane that also can cause magnetite dissolution [22]. In spite of that, clear relationships between anisotropy degree and direction in the KCES and millennial events still exist.

Combined with elemental chemistry, sediment grain size, color reflectance and rock magnetic parameters, AMS under redox conditions and its response to different environments are discussed below. Distinguishing the signals of reducing conditions and different geochemical and sedimentological parameters using rock magnetic parameters is crucial to accurately interpret paleoenvironments. This paper focuses only on the relationship between AMS and bottom currents. Other rock magnetic proxies related to climate will be discussed in a future paper.

\section{Materials and methods}

$\operatorname{KCES}\left(35^{\circ} 56.150^{\prime} \mathrm{N}, 130^{\circ} 41.915^{\prime} \mathrm{E}\right.$, water depth of 1463.8 $\mathrm{m}$ and length of $10.30 \mathrm{~m}, 15$ cores) lies on the southern slope of the Ulleung Basin, on the path of the Tsushima Current. The core was provided by the Korean Ocean Research and Development Institute (KORDI). Photographs and X-radiographs were collected by KORDI, and color reflectance, magnetic susceptibility and sample splitting were undertaken at the First Institute of Oceanography. Detailed descriptions of sediments were reported in Liu et al. [19].

A side length of $2 \mathrm{~cm}$ of each cube was used for sampling. The sediment was partially dry and some cleavage occurred at the time of our sampling. The reported depth was taken at a middle position of a sample, subtracting the width of cleavage (the so-called adjusted depth). AMS was measured on KLY Kappabridge along the $X-Y-Z$ direction. Then, magnetic susceptibility, declination and inclination of three principal axes, anisotropy degree, lineation and foliation were obtained. Anhysteresis remanent magnetization (ARM) was acquired with a $80 \mathrm{mT} / 0.05 \mathrm{mT}$ alternate and biasing field. Saturation remanent magnetization (SIRM) by $1 \mathrm{~T}$ direct field, and a backfield of $0.1 \mathrm{~T}$ and $0.3 \mathrm{~T}$ direct field were added to obtain $S$ ratios $\left(S_{-0.1 \mathrm{~T}}=\mathrm{IRM}_{-0.1 \mathrm{~T}} / \mathrm{SIRM}_{1 \mathrm{~T}}\right.$, $S_{-0.3 \mathrm{~T}}=\mathrm{IRM}_{-0.3 \mathrm{~T}} / \mathrm{SIRM}_{1 \mathrm{~T}}$ ). Powder samples were heated in air to reveal temperature dependent changes of magnetic susceptibility on the Kappabridge KLY-3s magnetometer. Magnetic loops with $1 \mathrm{~T}$ highest field were measured with a Micromag 3900 magnetometer. All the magnetic work was undertaken at the Institute of Geology and Geophysics, Chinese Academy of Sciences (Beijing).

\section{Results}

\subsection{Anisotropy of magnetic susceptibility}

Due to the fact that cores are not absolutely oriented, and there is a relative rotation between them, we had to adjust AMS with paleomagnetic directions before interpreting their environmental significance. We adopted the method of Parés et al. [9], where the rotation angle is the angle between the horizontal component of characteristic remanence and the reference line. For the latter, we chose $0^{\circ}$. The assumption of this adjustment is that the axial geocentric dipolar nature of the geomagnetic field is in agreement with the magnetic pole and the geographic pole. A relative declination of $118^{\circ}$ of the first core (surface) was subtracted from the declination of the three axes. Unfortunately, the relative orientation of the remanence and AMS was not the same, and a further clockwise $180^{\circ}$ rotation was added. Thus, the first core needed to rotate $62^{\circ}$ to obtain the absolute direction of the AMS by combining the two angles. Rotation angles of the rest of the cores could be deduced by analogy (Table 1). The reoriented AMS axes are presented in Figure 1(a).

The declination and inclination of the principal axes of AMS were completely different above and beneath $7.31 \mathrm{~m}$. The normal sedimentary pattern was observed in the upper part, with the long axis close to the bedding plane and the short axis nearly vertical (Figure 1(a)). Some clearly shallow inclinations usually reflected slight disturbance, such as in the first sample near the surface. However, there were others that did not show signs of disturbance (\#79). Under 
Table 1 The rotation angles for different cores in the KCES

\begin{tabular}{|c|c|c|c|c|c|}
\hline $\begin{array}{c}\text { Core } \\
\text { number }\end{array}$ & $\begin{array}{l}\text { Sample } \\
\text { number }\end{array}$ & $\begin{array}{c}\text { Averaged declination } \\
\text { of remanence }\left({ }^{\circ}\right)\end{array}$ & $\begin{array}{c}\text { Averaged inclination of } \\
\text { remanence }\left({ }^{\circ}\right)\end{array}$ & $\begin{array}{l}\text { Angle for remanence } \\
\text { measuring placement }\end{array}$ & $\begin{array}{l}\text { Adjust angle for AMS to } \\
\text { geographic north }\left(0^{\circ}\right)\end{array}$ \\
\hline 1 & 21 & 118 & 52.25 & +180 & +62 \\
\hline 2 & 10 & 118 & 55.65 & & +62 \\
\hline 3 & 22 & 237 & 56.48 & & -57 \\
\hline 4 & 22 & 244 & 51.78 & & -64 \\
\hline 5 & 21 & 87 & 58.70 & & +93 \\
\hline 6 & 9 & 276 & 52 & & -96 \\
\hline 7 & 1 & 120 & 51 & & +60 \\
\hline 8 & 19 & 13 & 45.7 & & +167 \\
\hline 9 & 9 & 1 & 40.45 & & +179 \\
\hline 10 & 2 & 40 & 54.3 & & +140 \\
\hline 11 & 18 & 336 & 40.7 & & $-156^{*}$ \\
\hline
\end{tabular}

*, + clockwise; - anticlockwise.

(a)
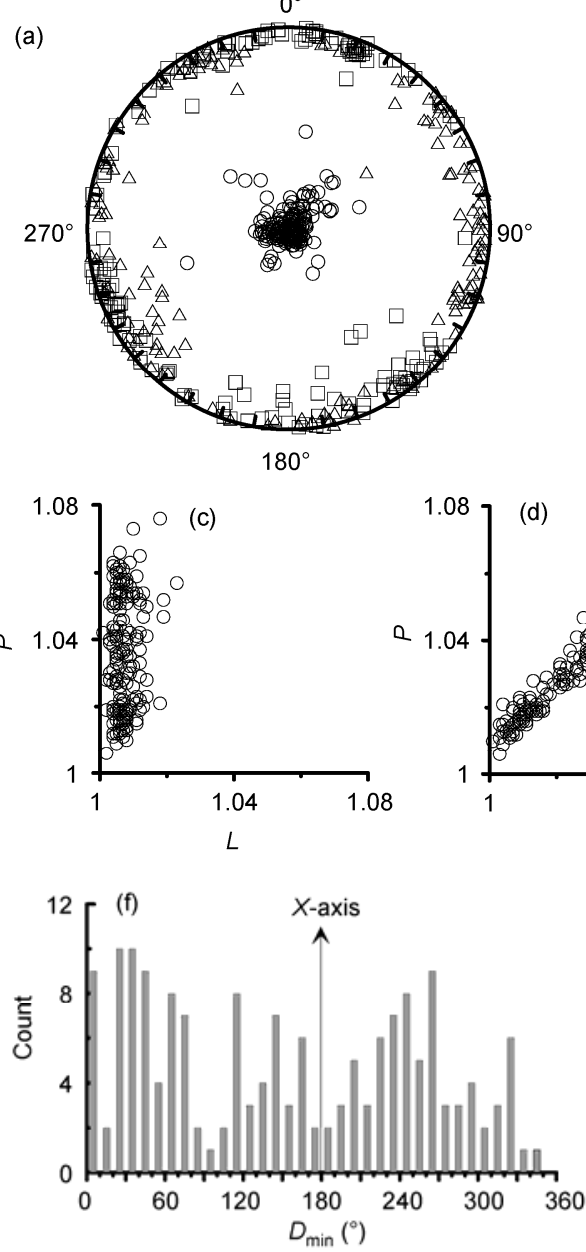
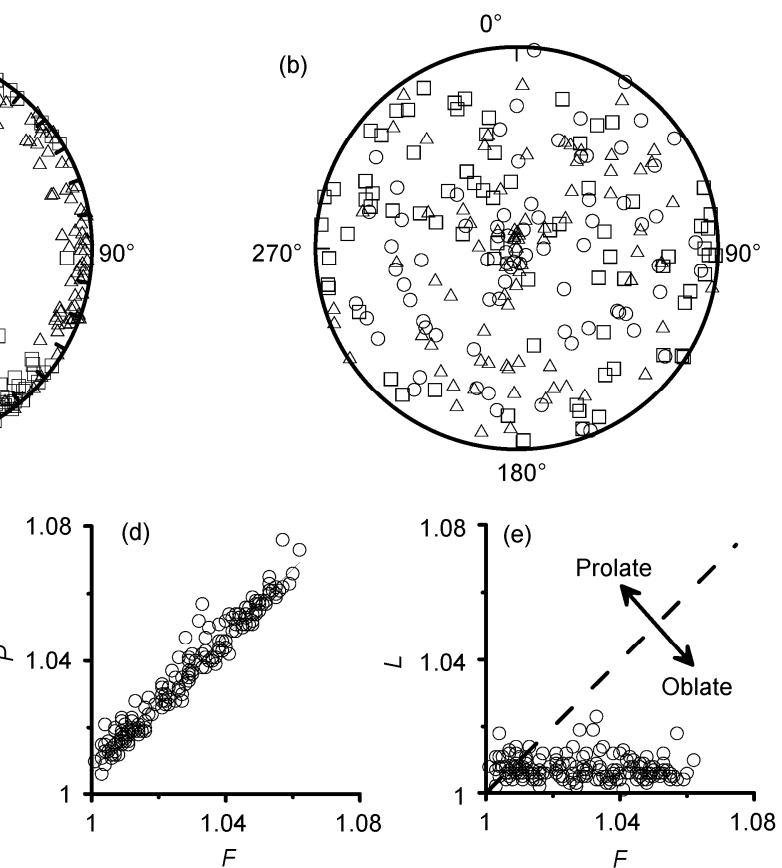

F

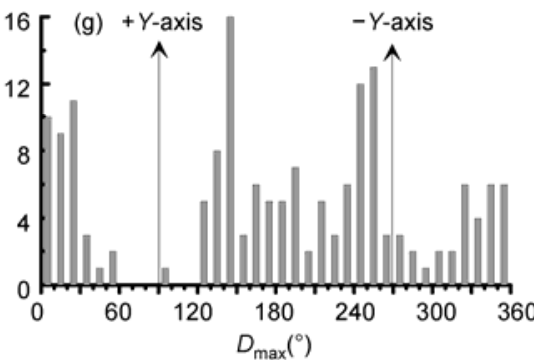

Figure 1 Distribution of three axes of AMS and other anisotropy proxies. (a) Lower hemisphere equal area projection of adjusted AMS axes: 1\# is the uppermost solid point, $6 \#$ and $86 \#$ behave as high anisotropy degree and abnormal inclination, and the latter even has high remanence, magnetic susceptibility and $\mathrm{S}$ ratios. In a check of the sampling record, we found artificial disturbance of two small pits at the surface of $6 \#$ and cleavage in $86 \#$, thus the two were deleted from the figure; (b) AMS distribution below $7.31 \mathrm{~m}$, not rotated; (c) Weak correlation of anisotropy $\left(P=K_{1} / K_{3}\right)$ and lineation $\left(L=K_{1} / K_{2}\right)$; $(\mathrm{d})$ Strong linear correlation of anisotropy and foliation $\left(F=K_{2} / K_{3}\right)\left(R^{2}=0.95, N=176\right)$; (e) Flinn plot to indicate shape or alignment, larger lineation for prolate and large foliation for oblate; (f) geographic distribution of short axis (no $X$ axis dominance); (g) geographic long axis distribution (no dominance in $+Y$ and $-Y$ directions) for $0-7.31 \mathrm{~m}$. 
$7.31 \mathrm{~m}$, the three principal axes were distributed randomly on the entire projection plane (Figure 1(b)). The abnormal AMS suggests that the original sedimentary structure has been completely destroyed. At the same time, the anisotropy degree, the foliation and the shape factor vary little, indicating mixing. Thus, the upper $7.31 \mathrm{~m}$ of the core was normal and original. The entire anisotropy degree for $0-7.31 \mathrm{~m}$ was smaller than 1.08, and not related to the lineation (Figure 1(c)). However, it was related linearly to the foliation (Figure 1(d)). Thus, the anisotropy was mainly foliation, indicating an oblate distribution of particles, which also are seen in Flinn plots of lineation and foliation (Figure 1(e)). The interval of low anisotropy was caused by reduction of foliation, and not lineation. Pares et al. [9] suggested that a typically disturbed AMS signal should be E-W elongated in the long axis [23] or N-S in the short axis, a result not supported by our KCES data (Figure 1(a), (f), (g)), thus removing the artificial influences of AMS in our core.

\subsection{AMS Evolution for the last $48 \mathrm{ka}$}

The age model is reported by Liu et al. [19] and Zou et al. [21], and the main tie points are from one AMS ${ }^{14} \mathrm{C}$ datum (N. pachyderma), four known tephra layers and one dark layer. From top to bottom, the four tephra layers are K-Ah (7.3 cal ka BP), U-Oki (10.69 cal ka BP), AT (29.24 cal ka $\mathrm{BP})$ and SKP-1 (40.5 cal ka BP). There is some difference in age of the dark layer reported by two authors. Zou et al.'s age model [21] was adopted just for convenience of comparison with geochemical proxies. To elucidate the following evolution more clearly, tie points for the age model are outlined in this paper (Table 2 and Figure 2). The sedimentation rate for the last $48 \mathrm{ka}$ is clearly not constant.

Based on the above age model, we can discuss rock magnetic evolution, including AMS (Figure 3). The magnetic susceptibility is low, around $1.8-6.4 \times 10^{-8} \mathrm{~m}^{3} \mathrm{~kg}^{-1}$ (not including the surface high). Three periods of MS change can be recognized. From 48-14.5 cal ka, except for a tephra layer, MS increases from $3.5 \times 10^{-8} \mathrm{~m}^{3} \mathrm{~kg}^{-1}$ to the highest value in this core. From 14.5-12 cal ka, MS drops abruptly

Table 2 Age model in the KCES

\begin{tabular}{cccll}
\hline $\begin{array}{c}\text { Depth } \\
(\mathrm{cm})\end{array}$ & Age (a) & Age (cal ka) & $\begin{array}{c}\text { Depth range } \\
(\mathrm{cm})\end{array}$ & Dating evidence \\
\hline 0 & & 0 & & Surface present \\
153 & $5090 \pm 35$ & $5.4^{*}$ & $150-156$ & Foram AMS $^{14} \mathrm{C}$ \\
180 & & $7.3^{*}$ & $179-181$ & K-Ah \\
253 & $10.69^{*}$ & $252-254$ & U-Oki \\
402 & $14.5^{* *}$ & & TL2 top \\
468 & $23^{* *}$ & & TL2 bottom \\
493 & $29.24^{*}$ & & AT \\
636 & $40.5^{*}$ & & SKP-1 \\
\hline
\end{tabular}

* From [19], ** from [21].

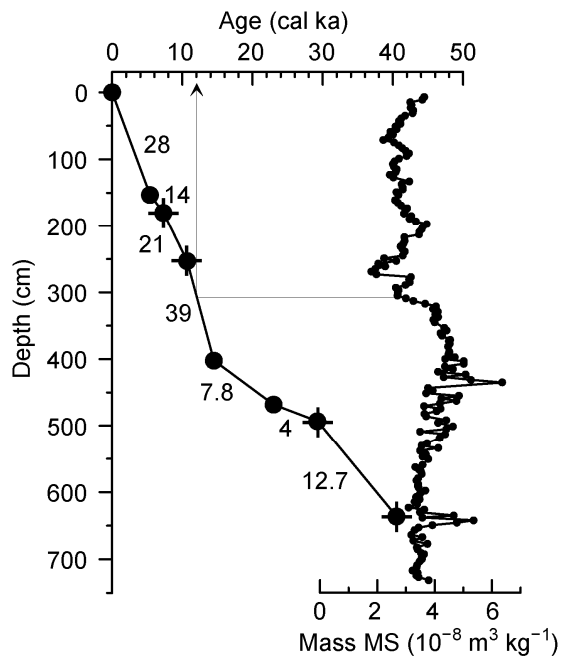

Figure 2 Age model and sedimentation rate in the KCES. The transition in MS occurs at $12 \mathrm{cal} \mathrm{ka} \mathrm{BP}$, and the number in the figure indicates the rate in $\mathrm{cm} / \mathrm{ka}$. The line of solid circles with crosses indicates the tephra age.

to $3 \times 10^{-8} \mathrm{~m}^{3} \mathrm{~kg}^{-1}$. From $12 \mathrm{cal} \mathrm{ka}$ on, MS is lower than $3.5 \times 10^{-8} \mathrm{~m}^{3} \mathrm{~kg}^{-1}$, and fluctuates with small amplitude (Figure $3(\mathrm{~g}))$. The peak MS value marks a transition from high to low MS and low to high sedimentation rate, implying an inverse relationship. The four tephra layers are clearly sandy, but not embodied in MS. Only the bottom SKP-1 shows a slight increase. The lack of change in MS in the other three samples may be explained by their greater distance from volcanic craters.

Shape factor $Q$ is close to 0 , indicating nearly identical long and intermediate axes, which are larger than the short axis, according to the definition (Figure 3). The first high $Q$ occurs at $6.8-0.24 \mathrm{cal} \mathrm{ka}$, with an average of 0.59 , and the second is between $14.3-11.9 \mathrm{cal} \mathrm{ka}$, averaging 0.6 . The two peaks occurred after the eruption of K-Ah and deglaciation at the end of MIS2. In the northern Japan Sea, Yamazaki found a $Q$ larger than 0.67 (or 0.7 in [6]), which indicates that sediments were disturbed [12]. However, we found that the high $Q$ value regions in our core corresponded to low degree of anisotropy, lineation and foliation. Lineation is low (around 1.01) and varies little. The smaller anisotropy degree is mainly reflected in the foliation (i.e. decreased $K_{\text {int }} / K_{\min }$ and constant $K_{\max } / K_{\text {int }}$, that is, less oblate) from 1.05 to similar values with lineation (Figure 3(d),(e)). Small values in lineation and foliation transform the ellipse to a sphere, and this shape may lower the alignment efficiency of particles, and cause high $Q$. We recognize that the selection of a definite $Q$ value as the standard of disturbance is a current issue in this field.

The two intervals of high $Q$ correspond to lower foliation and anisotropy (Figure 3(d),(e)). It is noteworthy that the lower high $Q$ interval has high sand (Figure 5(k)) and silt contents (not shown in the figure, but similar to the sand trend) and low clay (Figure 5(j)); while the upper high $Q$ area has no size variation. Although similar in high $Q$ 
(a)

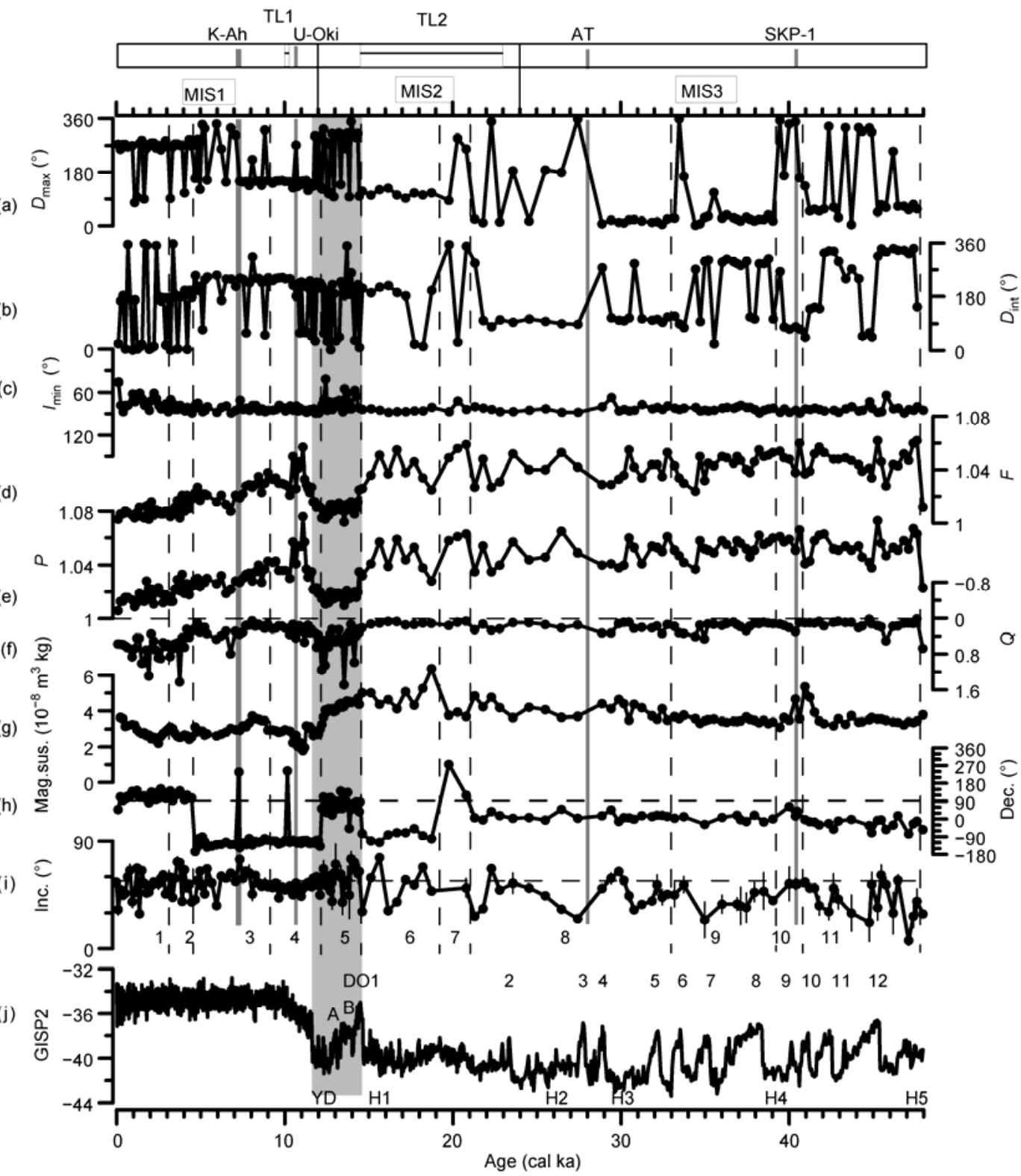

Figure 3 AMS parameter evolution in core KCES. (a) Declination of $K_{\max }$; (b) declination of $K_{\text {int }}$; (c) inclination of $K_{\min }$; (d) lineation; (e) anisotropy degree; (f) shape factor $Q=\left(K_{1}-K_{2}\right) /\left[\left(K_{1}+K_{2}\right) / 2-K_{3}\right]$; (g) mass magnetic susceptibility; (h) characteristic declination; (i) inclination and angle error by principle component analysis. The core break is indicated by a dash line, numbers near inclination are the core numbers, dash line in Inc curve is the axial dipolar latitude 51, inclinations for the last 15 cal ka are basically around it; (j) GISP2 ice core oxygen isotope [24]. The millennial warm events DO1-12 and cold events are marked above and under the GISP2 curve. The lithology scheme at the top of entire figure show positions of four tephra layers, dark lamination TL1 and TL2.

and low foliation, the two intervals may have different formation reason. The former interval with coarsened grain size may imply source or dynamic change. The latter interval has no size change and may have been caused by postdepositional modification. The declination of $K_{\max }$ and $K_{\text {int }}$ (Figure 3(a),(b)) and inclination of $K_{\min }$ (Figure 3(c)) change concordantly with the lower abnormity of $Q$ and foliation. However, on the upper abnormity of $Q$ and $F$ $(6.8-0.24 \mathrm{cal} \mathrm{ka})$, the declination of $K_{\max }$ and $K_{\text {int }}$ swing between normal and "abnormal", and $K_{\min }$ departs from vertical (Figure 3(a)-(c)). The three known tephras (K-Ah, U-Oki and SKP-1) have slightly higher $Q$ and lower $F$ (Figure 3(d),(f)). Declinations of characteristic remanence clearly rotate between cores (Figure 3(h)) and inclination basically hovers around the expected dipolar latitude for the last $14.5 \mathrm{cal} \mathrm{ka}$, shows a larger amplitude before $14.5 \mathrm{cal} \mathrm{ka}$ $\mathrm{BP}$, and an even larger one before $33 \mathrm{cal}$ ka BP (Figure 3(i)). Most samples have clear demagnetization curves and are uni-component in character, with only a few also yielding second components (Figure 4, 90\#, 158\#). 

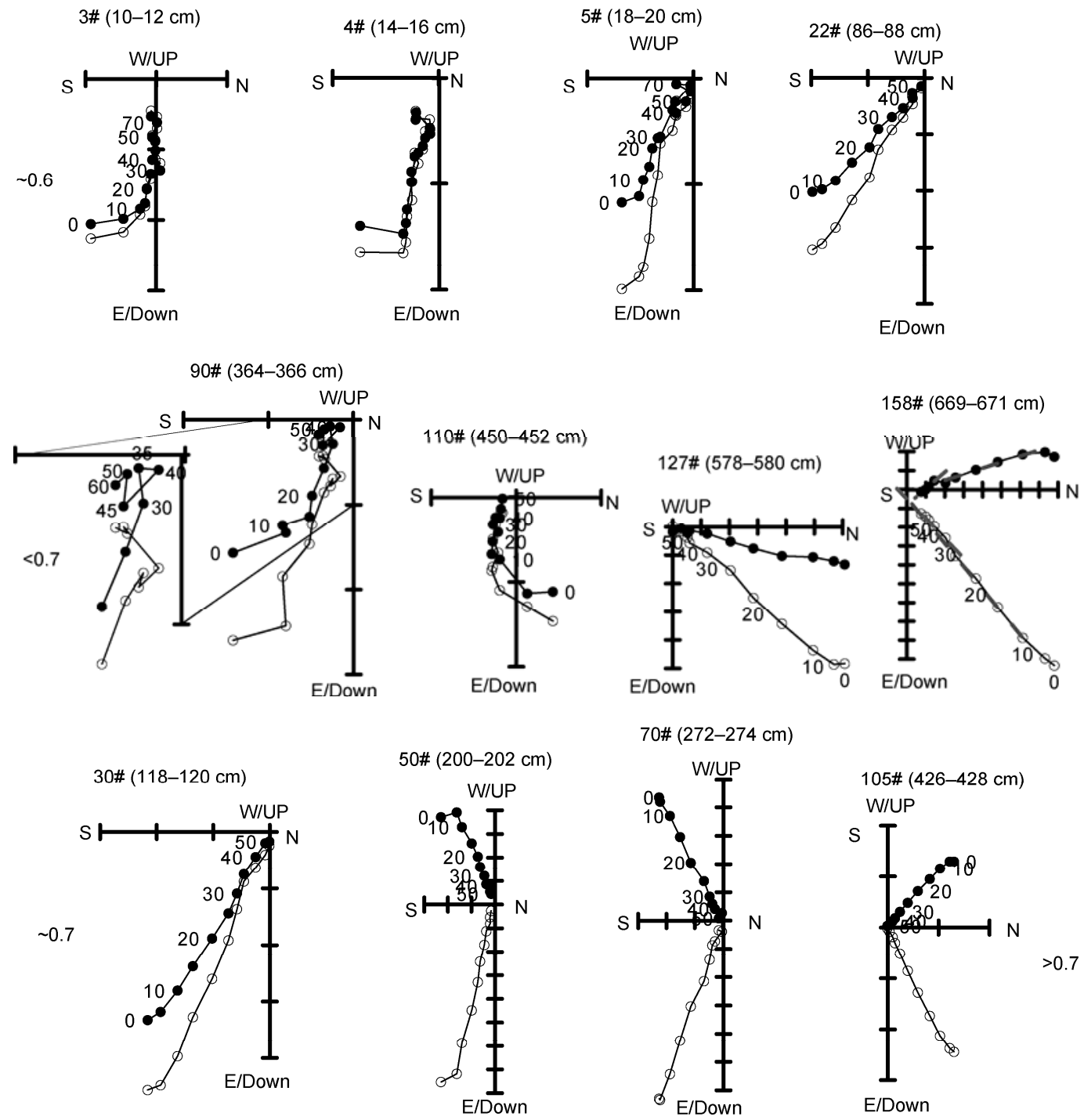

$$
70 \#(272-274 \mathrm{~cm})
$$
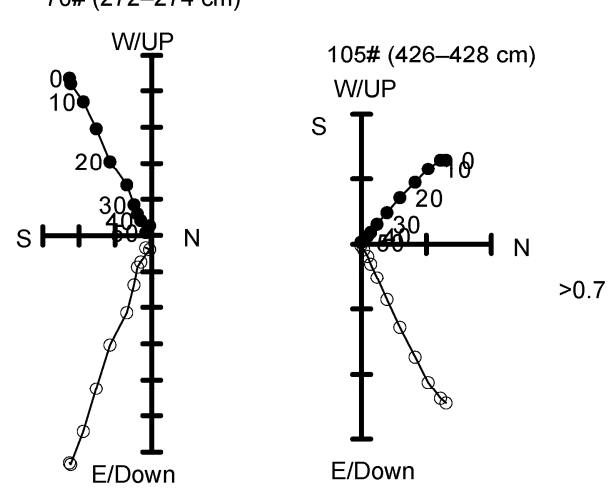

$100 \#(406-408 \mathrm{~cm})$
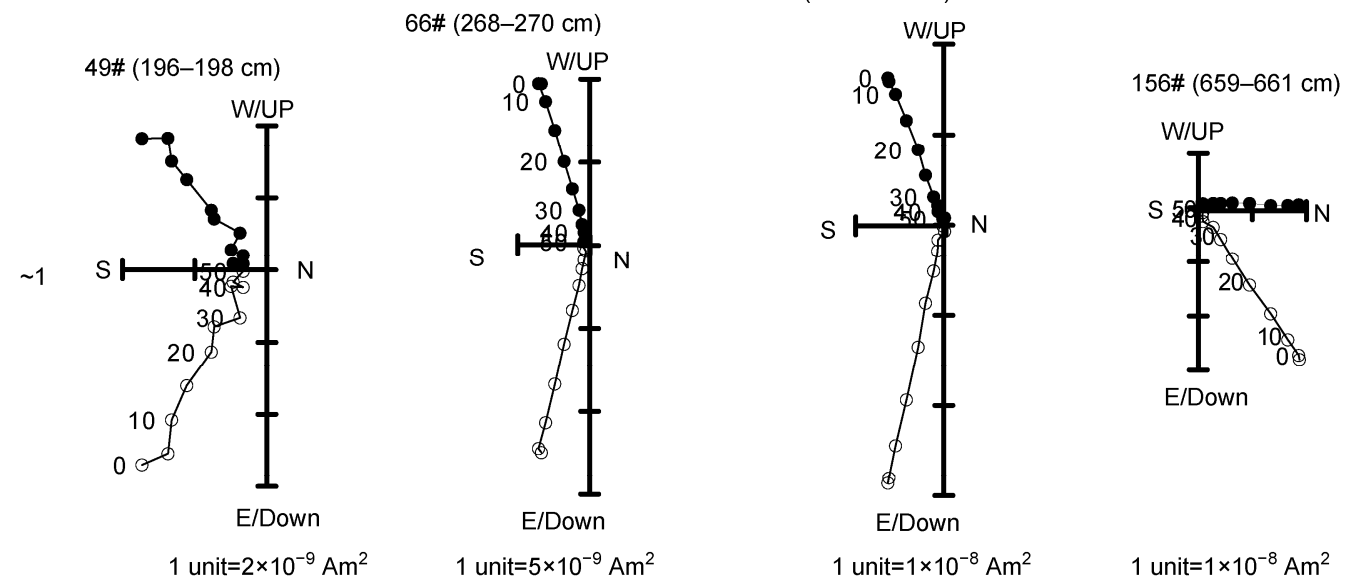

Figure 4 Vector projections of samples with different $S_{-0.1 \mathrm{~T}}$ values in core KCES. Open and solid dots represent vertical and horizontal planes, respectively. Numbers in the figure are the fields in $\mathrm{mT}$. The units are different for top and bottom samples, and the unit of samples without marks is $1 \times 10^{-9} \mathrm{Am}{ }^{2}$. 


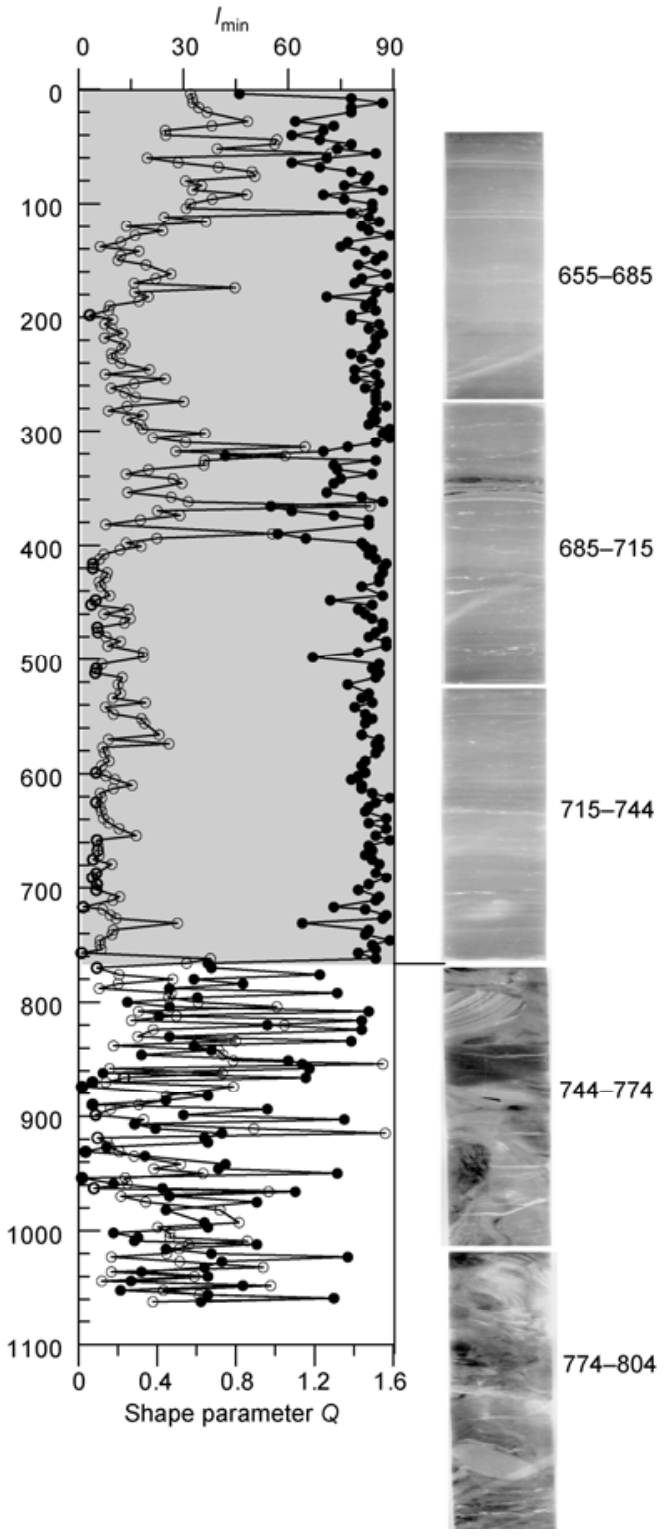

Figure 5 Inclination of $K_{\min }$ (solid circles) and shape factor (open circles), and the representative interval of an X-radiograph. Depth is the unadjusted depth for comparison with the radiograph. Shrinkage during drying changed the original 744 to $731 \mathrm{~cm}$.

\section{Discussion}

\subsection{The Sedimentary AMS and Indication of a Turbidite}

About 48 cal ka B P, a 3 m thick deposit of chaotic sediments accumulated on the southern slope of the Ulleung Basin (base not seen). The short axis of AMS and the shape factor are both abnormal (Figure 1(b)), and indicate completely disturbed sedimentary structures. In addition, the $\mathrm{X}$-radiographs indicate presence of conglomerate, distortion and cleavage, which are completely different to the upper part (Figure 5). We noticed an excellent correspondence between abnormal $K_{\min }$ and a shape factor with distortion, and cleavage development in the X-radiographs. The color turns from upper gray green to gray yellow, but no distortion can be observed visually. Both color and X-radiographs imply that a large slump or turbidity current occurred before $48 \mathrm{cal} \mathrm{ka}$ in the Ulleung Basin, and sediments from the shelf and upper slope slumped to cover the foot of slope. Our core study indicates that X-radiographs are useful in detecting hidden structures and in recognizing bedding or disturbance.

Previous reports indicate that sediments related to slope instability are very common on the south slope of the Ulleung Basin. The trend is from slump at the upper slope to debris flows or turbidites in the middle and lower parts of the slope. Slope instability took place in the last glacial before the Holocene. The cause of this instability was increased sedimentary pore pressures or storm wave erosion [11]. Excess pore pressure may have been related to eustatic pressure reduction due to lower sea level and/or dissociation of gas hydrates. The shallowest water depth for gas hydrates is $300-400 \mathrm{~m}$, which is consistent with the top of the slump area in the Ulleung Basin [11]. Conglomerate deposition before $48 \mathrm{cal} \mathrm{ka}$ on the south slope of Ulleung Basin verifies previous studies.

\subsection{AMS evolution and its relationship with early diagenesis and climate change}

Kissel et al. [7] summarized the factors that may affect AMS in the Norwegian Sea and North Atlantic sediments, including source ferromagnetic or paramagnetic variations (original and diagenetic), bioturbation, compaction and climatic controls. The authors removed the former three factors and concluded that the environment can largely change AMS. This is because AMS shows an elevated anisotropy and oblateness during warm and interglacial periods. The question then remains with respect to what can be deduced by the AMS signal in our core.

(1) Imprint of early diagenesis. First, we considered the highest magnetic content at the surface to be contamination. However, a later examination found a simultaneous increase in size parameters (ARM/SIRM) and $S$ ratios. Below the surface, ARM and SIRM decrease continuously, and $S_{-0.3 \mathrm{~T}}$ drops from 0.96 to 0.85 and back to 0.9 when remanences stop decreasing. The synchronous changes of ARM/SIRM and $S_{-0.3 \mathrm{~T}}$ indicate a continuous shift from fine to coarse magnetite (Figure 6(e)-(i)), and the lowest values of ARM/ SIRM and $S_{-0.3 \mathrm{~T}}$ coincide at the same stratum. This continuous process cannot be fully explained by surficial disturbance. The isochronous variations of magnetic mineralogy and size imply a common cause, either from alternate coarse, high coercivity and fine, low coercivity magnetic minerals, or from selective dissolution of fine magnetite by early diagenesis. After the Holocene maximum (5-7 cal ka), dynamic conditions in the Japan Sea already resembled those of modern times. Also, there was no big variation of source or dynamics, which is supported by stable $\mathrm{TiO}_{2}$ content [20] 


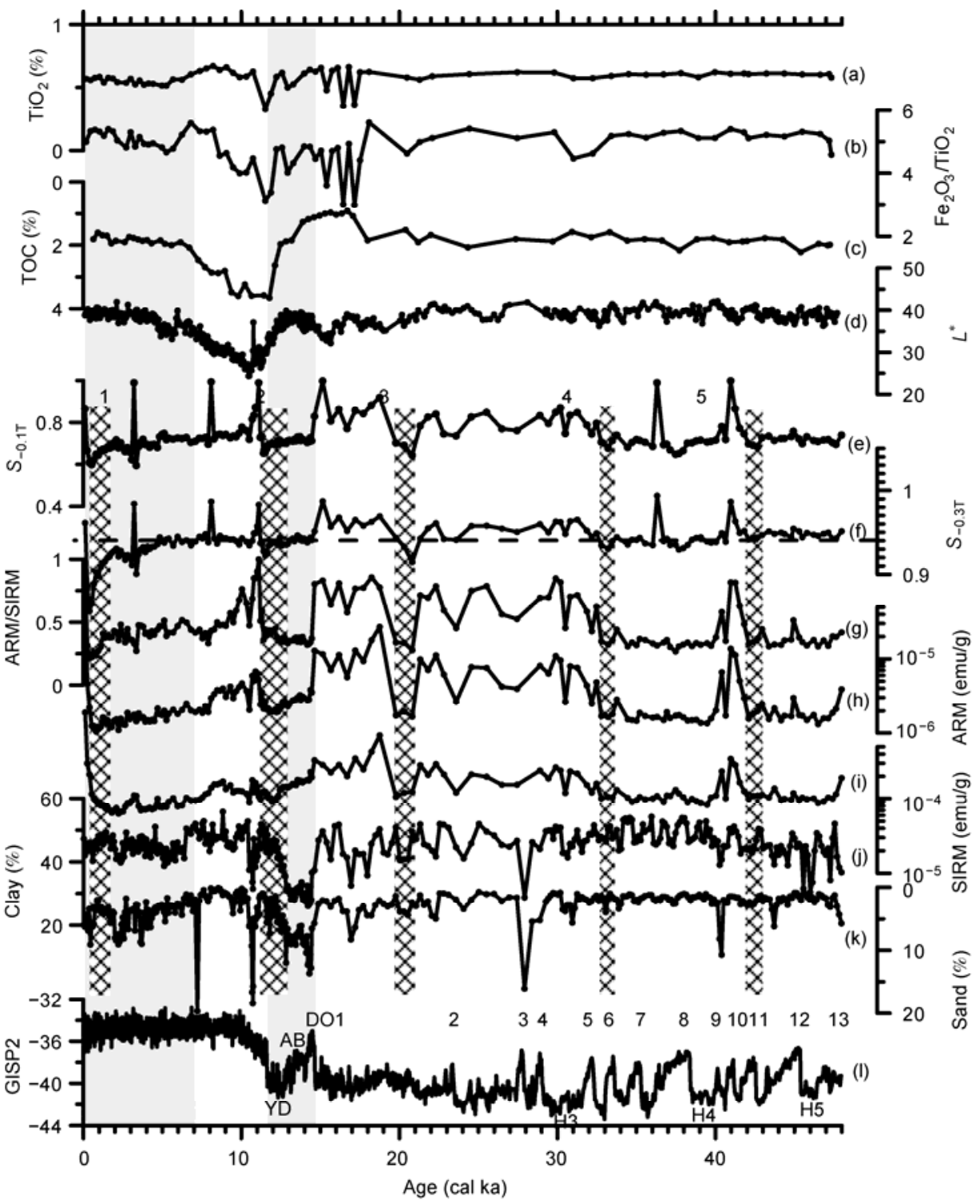

Figure 6 Rock magnetic behavior with early diagenesis, clay, sand and geochemical proxies. (a) $\mathrm{TiO}_{2}$; (b) ratio of total $\mathrm{Fe}$ and $\mathrm{TiO}$; (c) $\mathrm{TOC}$ [20]; (d) reflectance $L^{*}$ (Wang K data); (e) $S_{-0.1 T}$; (f) $S_{-0.3 T}$; (g) magnetic size indicator ARM/SIRM; (h)ARM; (i) SIRM; (j) clay content; (k) sand content in sediment [19]; (1) GISP2 ice core oxygen isotopes. Long gray shaded areas are the two low-anisotropy intervals, and short gray shaded areas are five redox belts according to $\mathrm{S}$ ratios, magnetic concentration and magnetic size.

and sediment grain size [19] in our core. In addition, during heating to $700^{\circ} \mathrm{C}$, a pungent odor and dark heating product were produced. All these phenomena can be interpreted with respect to early diagenesis. The drop of $S$ ratios near the surface indicates a prior dissolution of fine grained magnetite, in agreement with coarsening of magnetic minerals. The similar rock magnetic properties also have been reported in core CSH of the Okinawa Trough [18], Korean continental shelf [17] and other continental shelf and slope sediments. The high-low-high $S$ ratios from top downwards correspond to shifts from oxygenated-transition-reducing horizons, respectively [14].

If the similar $S$ ratio patterns described above are the redox record, then the redox belt can extend beyond the sea- floor surface (Figure 6(e),(f)). Removing obvious disturbances (86\#), core breaks (23\#) and isolated points (no consistent changes at ARM/SIRM and remanence, 49\#, 140\#), there are four other similar intervals (Figure 6(e),(f) gray belt). Although the four belts have higher $\mathrm{S}$ ratios than the surface, they are all minima of neighboring values. Survival of buried $S$ ratio maxima near 1 (oxygenated belt) in the sediments of the Japan Sea indicate that anoxia may have been confined to near water-sediment boundaries and rapid sedimentation may have moved sediment quickly across this transition to preserve the redox boundary in the core. Different values in $S$ ratios may infer different degrees of reducing conditions. The strongest reducing state is near the surface, followed by the second reducing belt, and then the 
three weaker belts at the lower part. The transition from weak to strong reducing state is accompanied by increasing sedimentation rates after $14 \mathrm{cal} \mathrm{ka}$, which may indicate an enhancement of reducing state by increasing sedimentation rates. In the first and second reducing belts, there are lower $P$ and higher $Q$ (Figure 3(e), (f)), and this may be caused by stronger dissolution of magnetite and the formation of new minerals. $S_{-0.1 \mathrm{~T}}$ smaller than 0.9 is linearly related with ARM/SIRM $\left(R^{2}=0.81, N=172\right)$, and this probably indicates an overwhelming influence with only weak diagenesis.

(2) Climate signals conserved. Given the ubiquitous existence of early diagenesis, the question remains regarding whether rock magnetic parameters still bear environmental and climatic signals. We attempted to analyze this problem, starting from the intervals of highest TOC and darkest $L^{*}$ (Figure 6(c),(d)). According to the GISP2 scale (Figure 6(1)), Greenland entered the Holocene warmest period after 11.6 cal ka BP. At 11.6-7 cal ka BP in our core, 4\% organic carbon and darkest color confirm the input of more organic carbon, which exhausted the oxygen in sediment and most likely caused the early diagenesis. However, $S$ ratios in this interval did not drop much, with relatively high ARM, SIRM and ARM/SIRM (Figure 6(g)-(i)). In the darkest sediments, a moderately low value of magnetic susceptibility occurred around $11 \mathrm{cal} \mathrm{ka} \mathrm{BP}$, while moderate highs in ARM, SIRM, ARM/SIRM and $P$ were present (Figures 3(e) and $6(\mathrm{~g})-(\mathrm{i}))$. At the same time, geochemical contents of $\mathrm{Fe}_{2} \mathrm{O}_{3}$ and $\mathrm{TiO}_{2}$ also were high and present evidence of increased terrigenous inputs (Figure 6(a),(b)). In addition, magnetic susceptibility around the $8.2 \mathrm{ka}$ BP cold event increased (Figure $3(\mathrm{~g})$ ). The two brief, low amplitude events are preserved in the darkest sediment and prove conservation of climate signals. The strongest early diagenesis revealed by rock magnetic parameters did not occur in the dark interval, but after 7 cal ka BP, and were strongest near the surface, which also showed the lowest $S_{-0.3 \mathrm{~T}}$ of 0.85 .

The strongest early diagenesis occurred neither at the highest TOC nor in the dark lamination in the Japan Sea core (Figure 3, TL2), and seems to indicate that TOC or ventilation alone cannot determine the degree of early diagenesis, which is possibly controlled by the combination of the two and other factors. For example, increased sedimentation rates and gas hydrate dissociation. Besides decomposition of organic carbon, methane also can produce diagenesis. Recent multi-channel seismic navigation shows the existence of gas hydrates in the Ulleung Basin [25]. If the latter is the cause of early diagenesis, then a transition in sulfate ion and methane content should be found in the pore water [22]. The core lithology description in our core shows that the surficial $0.1 \mathrm{~m}$ is brown gray, and green gray underneath. This is more consistent with the color variation of brown-tan-green in early diagenetic sediments [14]. The general trend of strong to weak downward diagenesis also is opposite to methane diagenesis because methane content is highest at depth in the sediment column. As mentioned in section 3.2(1), the first and second reducing belts have lower $P$ and high $Q$ and may be related to diagenesis. The longest period of low $P$, equivalent in age with cold event YD, warm Allerød, Bølling and DO1 events, did not completely result from early diagenesis (Figure 3, gray belt). The low $P$ during 14.5-11.6 cal ka is synchronous with high silt and sand content (Figure $6(\mathrm{k})$ ), and also with low $\mathrm{TiO}_{2}$ and $\mathrm{Fe}_{2} \mathrm{O}_{3}$ (Figure 6(a),(b)), which is explained by chaotic accumulation of coarse grained sediments, driven by source or dynamic changes. The reducing state occurred during the upper YD event, and resulted in low $P$ and high $Q$ in only minor areas (Figure 3(e),(f)), with little effect on the entire $P$ pattern.

Enhanced bioturbation in warm periods may reduce anisotropy $P$, and compaction may increase oblateness $F$, but these trends were not found in our core. Thus, the magnetic content and size variation still reasonably preserve long and short term environmental changes. Only at the surface, with the strongest diagenetic modification, does the decreasing magnetic signal upwards reflect increasing degree of diagenesis, inconsistent with stable temperatures for the last 7 cal ka. In addition, rock magnetic parameters for $48-7$ cal ka BP still record environmental variation.

\subsection{AMS Direction during different climate periods in the last 48 ka and their significance}

In recent years, we systematically have collected AMS data from marine sediments, but only general principles have been discovered. The reasons for this may have been the varying dynamic conditions, physical mineral properties, composition and alignment. In most cases, AMS patterns only are statistically useful in judging disturbance or bottom current indications (Zhu Rixiang, pers. comm.). Thus, there is no simple relationship between alignment patterns of AMS and bottom currents. Surprisingly, the results from our core show that AMS measurements in the Japan Sea can indicate turbidity. Furthermore, in non-disturbed sediments, the long and intermediate axes all have prior direction and are perpendicular with each other (Figure 1(a)), which is that of a naturally floating and oblate alignment in quiet water.

The direction of paleocurrents is determined by the tilt between bedding planes and the direction of AMSs. Foliation (plane of long and intermediate axes) usually is parallel to the bedding plane, and lineation (long axis) is parallel or normal to the paleocurrent direction. For fine sediments, such as silt-clayey silt, the paleocurrent direction is tilting of the short axis relative to the horizontal plane [26,27]. Under moderate to low currents $(<1 \mathrm{~cm} / \mathrm{s})$, paleocurrent directions point to the compound vector of the short axis and bedding plane [26]. Under weak dynamics, the angle between the best fit plane of the long and intermediate axes and bedding plane do not exceed $25^{\circ}(1-0.1 \mathrm{~cm} / \mathrm{s})$, or $10^{\circ}(<0.1 \mathrm{~cm} / \mathrm{s})$. In the first case, the long axes also may be paralleled to the 
current. For grains carried by high velocity currents, the long axes of which are normal to the current, and intermediate and short axes are randomly distributed in the parallel plane of the current [4]. For slope sediments, grains usually roll down the slope, with long axes parallel to the bedding plane [28]. Tarling and Hrouda [28] further pointed out that antipodal distributions of long axes parallel to currents are formed under velocities slower than $1 \mathrm{~cm} / \mathrm{s}$. Moreover, when velocities are greater than $1 \mathrm{~cm} / \mathrm{s}$, girdle distributions occur and tilt toward the upstream direction. Ellwood [4] found that the long axis of AMS is parallel to contourites in the southeast Indian Ocean, and Liu et al. [6] suggested that the long axis in tidal sediments of Changjiang Estuary indicate the tidal direction. On the Gardar drift of the North Atlantic, previous studies indicate long axis transit at 0.90 $\mathrm{Ma}$, an east-west direction from 1.6-0.90 Ma, and a NNESSW orientation from $0.90-0.40 \mathrm{Ma}$, the latter coincides with bottom current directions revealed by mud varves $[29,30]$. Thus, the long axis of AMS was interpreted as the bottom current direction.

In the age model of Table 2, the paleomagnetically oriented AMS show variations in different climate periods (Figure 7). At 48.0-45.3 cal ka BP, when the DO13 warm event and H5 cold event in GISP2 took place, the girdle patterns of the long and intermediate axes distributed near the horizon (inclination $<10^{\circ}$ ), the short axis was almost vertical and no obvious tilt was evident, except for in sample (172\#) (Figure 7(i)-10). The girdle of the long and intermediate axes may imply currents greater than $1 \mathrm{~cm} / \mathrm{s}$, and if the direction of 172\# is adopted, the current direction should be SSW $\rightarrow$ NNE. At 44.9-42.7 cal ka BP, the time of the warm DO12 and cold unnamed event (here referred as H4.3), the long and intermediate axes are close to the horizontal plane $\left(<10^{\circ}\right)$, and the short axis is vertical, but the former two axes are neither focused nor antipodal over a wide area of W-S (Figure 7(i)-9). Slight departures of 168\# may be explained by low $P$ (Figure $7(\mathrm{c})$ ) or increasing velocities. If the tilt of this sample and others is taken as the current direction, then it is still the same as in DO13 and H5 (SSW-NNE). At 42.3-41.2 cal ka BP and 40.6-39.5 cal ka BP, equivalent with DO11-10 and DO9 and H4 (Figure 7(i)-7-8, (a)), no visible tilt of short axes is apparent, and the long axis turns from NWW to NNE-SSW, suggesting a direction change and slowing of currents. At 39.1-21.3 cal ka $\mathrm{BP}$, frequent millennial events occurred, including DO8-2, H4-1 and LGM (Figure 7(a)), but the water current was very stable, indicated by a long axis positioning of SWW-NEE. Except for three samples, the long axes of most samples were focused at one side (Figure 7(i)-6, three samples are $115,117,118)$, indicating a greater current than 1 $\mathrm{cm} / \mathrm{s}$, but a brief slowing of currents may have taken place in the $\mathrm{H} 1$ event (Figure 7(a)).

At 21.3-19.8 cal ka BP, the LGM terminated and climate slowly turned to post-glacial. Basically, a normal AMS structure is evident in this interval. Some samples deviated from the vertical position, which may imply dynamic strengthening and a NEE direction (Figure 7(i)-5). A dramatic fall in remanence and coarse grains may be explained by winnowing and may have resulted in weakening in magnetism. At 18.8-14.6 cal ka BP, the OD event took place and climate deteriorated. AMS was normal and the long axis was in the NNW direction (Figure 7(i)-4). A slight tilt was apparent along the NEE-SWW direction of the short axis, which may indicate the possible current direction. At 14.4-12.2 cal ka BP coinciding the time for DO1, BA warm events and YD cold events, AMS showed the largest scatter in this core. Long and intermediate axes deviated from the horizontal position by over $10^{\circ}$, and the short axis departed from the vertical position by over $10^{\circ}$ or even $30^{\circ}$ (e.g. $92 \#$, $96 \#, 90 \#, 91 \#$ to NW, $85 \#, 87 \#$ to NE, $79 \#, 81 \#, 84 \#$ to the SW; Figure 7(i)-3). Although the long axis was maintained in the previous NNW-SSE direction, the scatter of principal axes and obvious tilting of the short axis strongly hint to a turbulent and strengthened bottom current. In the sea level curve of the West Pacific, this time is indicated by a drastic rise in sea level and melt water pulse event MWP-1A [31]. The scatter of principal axes corresponds to the lowest $P$ (Figure 7(c)) and sand content increase. Systematic deviations of several samples toward different directions, and enhanced dynamic conditions, are verified by a coarse grain accumulation. Thus, the possibility of artificial disturbance could be eliminated. Low $P$ may indicate lowered alignment efficiency, but the drastic direction changes still point to the bottom current direction and its relative amplitude.

In the Early Holocene from 12.1-4.7 cal ka BP, when temperature rose continuously, AMS inherited the former direction and the antipodal long axis lay along the NNESSW direction, showing slower currents $(<1 \mathrm{~cm} / \mathrm{s})$ than before. Sample $45 \#$ is the U-Oki tephra, and a slight abnormity occurs (Figure 7(i)-2) there. At 4.5-0 cal ka BP, the long axis turned to the NW-SE, and the short axis tilted to the NE. Since the early diagenesis discussed in 3.2(1) had the largest degree at the surface, we also found scatter of AMS in small $S$ ratio intervals, but no ambiguity and difference in direction. In the Japan Sea, in situ measurements showed an anticlockwise cyclonic circulation deeper than $1000 \mathrm{~m}$, and sub-cyclonic circulations developing in the Japan, Yamato and Ulleung basins [32]. The core is located on the southern margin of the Ulleung Basin, where a sub-cyclonic, bottom current is oriented to the E and NEE. Thus, the tilting short axis is in agreement with the bottom current direction. The first sample 1\# and core break sample 23\# show clear deviations from the vertical position (Figure 7(i)-1), but they are separated and different with systematic deviations of several samples.

In summary, during $14.4-12.2 \mathrm{cal} \mathrm{ka}$ and $4.5-0$ cal ka, the short axis was clearly tilted and pointed to the absolute bottom current of SW, NW, NE and NEE. Although surface sediments were modified by early diagenesis, the direction still was preserved. In other periods than the above two, tilt 

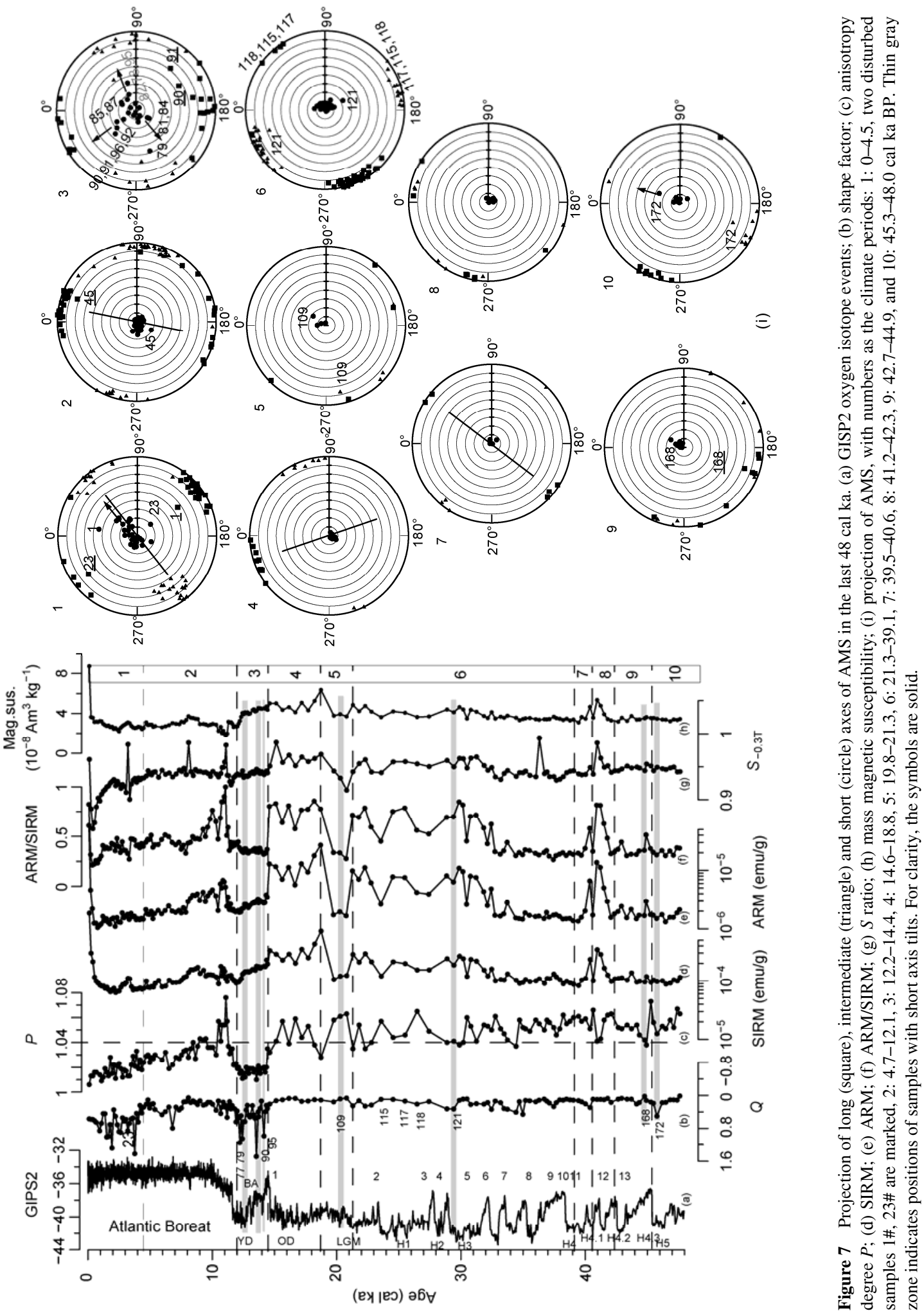
of the short axis was not clear or only one sample tilted (19.8-21.3, 42.7-44.9, 45.3-48.0 cal ka BP). Thus, if we take the long axis of these intervals as the current directions (Figure 7(i)), the bottom currents turned from NWW-SEE (48-41.2 cal ka BP) to NE-SW (41.2-21.3 cal ka BP) in the last $48 \mathrm{cal} \mathrm{ka}$. Then, the directions changed to near N-S at $18.8 \mathrm{cal} \mathrm{ka} \mathrm{BP,} \mathrm{to} \mathrm{NEE} \mathrm{at} 4.5 \mathrm{cal} \mathrm{ka} \mathrm{BP}$ and later.

\section{Conclusions}

(1) Three principal axes of AMS revealed turbidite and normal deposition on the south slope of the Ulleung Basin of the Japan Sea before and after 48 cal ka BP.

(2) AMS for the last 48 cal ka was that of a normal sedimentary structure: long and intermediate axes were close to the horizontal bedding plane, and the short axis was nearly vertical.

(3) The anisotropy of KCES was small and was predominated by foliation, not lineation, which was evidence of a compacted structure. The drop in anisotropy mainly was caused by foliation, and lineation varied little.

(4) A common occurrence of early diagenesis was found throughout the core, and degree of magnetite dissolution was not proportional with TOC and bottom water stagnation. The combination of the two factors and other factors, such as sedimentation rates, may be the determinants of early diagenesis. Although there was imprinting of early diagenesis, the small-amplitude and short-term climate events and original direction of AMS still survived.

(5) The long axis of AMS in the last 48 cal ka highlights millennial climate events. The current direction implied by long or short axes changed frequently during the last glacial, post-glacial and Holocene. In the most unstable period of the DO1-BA and YD events, bottom current direction and strength varied frequently and coarse grains accumulated. The last 4.5 cal ka was characterized by a tilt of short axes to the $\mathrm{E}$ (NEE), which is consistent with the bottom current measured.

The samples, X-radiography and photographs in this paper were provided by Professor SUK Bong-Chool in KORDI. Thanks also are extended to Wu Yonghua, Han Yibing, Lu Yao for their aid during lab sampling. The work was supported by the International Cooperation Program (40710069004), the Key Program (40431002), the Ordinary Program (40876036, 41076038) from the National Natural Science Foundation of China and the Basic Research Program of the First Institute of Oceanography (2007T09).

1 Mathé P E, Rochette P, Vandamme D, et al. Volumetric changes in weathered profiles: iso-element mass balance method questioned by magnetic fabric. Earth Planet Sci Lett, 1999, 167: 255-267

2 Rosenbaum J, Reynolds R, Smoot J, et al. Anisotropy of magnetic susceptibility as a tool for recognizing core deformation: Reevaluation of the paleomagnetic record of Pleistocene sediments from drill hole OL-92, Owens Lake, California. Earth Planet Sci Lett, 2000, 178: 415-424

3 Housen B A, Kanamatsu T. Magnetic fabrics from the Costa Rica margin: Sediment deformation during the initial dewatering and un- derplating process. Earth Planet Sci Lett, 2003, 206: 215-228

4 Ellwood B B. Application of AMS method as an indicator of bottom water flow direction. Mar Geol, 1980, 34: M83-M90

5 Ledbetter M T, Ellwood B B. Spatial and temporal changes in bottom-water velocity and direction from analysis of particle size and alignment in deep-sea sediment. Mar Geol, 1980, 38: 245-261

6 Liu B, Saito Y, Yamazaki T, et al. Anisotropy of magnetic susceptibility (AMS) characteristics of tide-influenced sediments in the late Pleistocene-Holocene Changjiang incised-Valley Fill, China. J Coastal Res, 2005, 21, 5: 1031-1041

7 Kissel C, Laj C, Mazaud A, et al. Magnetic anisotropy and environmental changes in two sedimentary cores from the Norwegian Sea and the North Atlantic. Earth Planet Sci Lett, 1998, 164: 617-626

8 Ge S L, Shi X F, Yang G, et al. Rock magnetic response to climatic changes in west Philippine Sea for the last $780 \mathrm{ka}$ : Discussion based on relative paleointensity assisted chronology (in Chinese). Quat Sci, 2007, 27: 1040-1052

9 Parés J M, Hassold N J C, Rea D K, et al. Paleocurrent directions from paleomagnetic reorientation of magnetic fabrics in deep-sea sediments at the Antarctic Peninsula Pacific margin (ODP Sites 1095,1101). Mar Geol, 2007, 242: 261-269

10 Aubourg C, Oufi O. Coring-induced magnetic fabric in piston cores from the western Mediterranean. In: Zahn R, Comas M C, Klaus A, eds. Proceedings of the Ocean Drilling Program, Scientific Results, Vol., 161, 1999. 129-136

11 Lee H J, Chough S K, Yoon S H. Slope-stability change from late Pleistocene to Holocene in the Ulleung Basin, East Sea (Sea of Japan). Sediment Geol, 1996, 104: 39-51

12 Yamazaki T, Abdeldayem A L, Ikehara K. Rock-magnetic changes with reduction diagenesis in Japan Sea sediments and preservation of geomagnetic secular variation in inclination during the last 30000 years. Earth Planets Space, 2003, 55: 327-340

13 Hayashida A, Hattori S, Oda H. Diagenetic modification of magnetic properties observed in a piston core (MD01-2407) from the Oki Ridge, Japan Sea. Paleogeogr Palaeoclimatol Palaeoecol, 2007, 247: 65-73

14 Karlin R. Magnetic mineral diagenesis in suboxic sediments at Bettis Site W-N, NE Pacific Ocean. J Geophys Res, 1990, 95, No B4, $4421-4436$

15 Leslie B W, Hammond D E, Berelson W M, et al. Diagenesis in anoxic sediments from the California continental borderland and its influence on iron, sulfur and magnetite behavior. J Geophys Res, 1990, 95, B4: 4453-4470

16 Roberts A P, Turner G M. Diagenetic formation of ferromagnetic iron sulphide minerals in rapidly deposited marine sediments, South Island, New Zealand. Earth Planet Sci Lett, 1993, 115: 257-273

17 Liu J, Zhu R, Roberts A P, et al. High-resolution analysis of early diagenetic effects on magnetic minerals in post-middle-Holocene continental shelf sediments from the Korea Strait. J Geophys Res, 2004, 109: B03103

18 Ge S L, Shi X F, Wu Y H, et al. Rock magnetic property of gravity core CSH1 from the northern Okinawa Trough and the effect of early diagenesis. Acta Oceanol Sin, 2007, 26: 54-65

19 Liu Y G, Shi X F, Suk B C, et al. The depositional environment in the southern Ulleugn Basin in the East Sea (The Sea of Japan) since the last 48000 a (in Chinese). Acta Oceanol Sin, 2010, 32: 94-106

20 Zou J J, Shi X F, Liu Y G, et al. Geochemical record of terrigenous sediments from the Sea of Japan since the last glacial and its response to sea level and climate change (in Chinese). Mar Geol Quat Geol, 2010, 30: 75-86

21 Zou J J, Shi X F, Liu Y G, et al. The geochemical record of paleoproductivity and paleoredox in the Sea of Japan since $48 \mathrm{ka}$ (in Chinese). Acta Oceanol Sin, 2010, 32: 98-109

22 Riedinger N, Pfeifer K, Kasten S, et al. Diagenetic alteration of magnetic signals by anaerobic oxidation of methane related to a change in sedimentation rate. Geochim Cosmochim Acta, 2005, 69: 4117-4126

23 Copons R, Parés J M, Dinarés-Turell J, et al. Sampling induced AMS in soft sediments: A case study in Holocene (glaciolacustrine rhythmites from Lake Barrancs (central Pyrenees, Spain). Phys Chem Earth, 1997, 22: 137-141 
24 Stuiver M, Pieter M. Grootes. GISP2 oxygen isotope ratios. Quaternary Research, 2000, 53: 277-284

25 Horozai S, Lee G H, Yi B Y, et al. Seismic indicators of gas hydrate and associated gas in the Ulleung Basin, East Sea (Sea of Japan) and implications of heat flows derived from depths of the bottomsimulating reflector. Mar Geol, 2009, 258: 126-138

26 Liu B, Saito Y, Yamazaki T, et al. Paleocurrent analysis for the Late Pleistocene-Holocene incised-valley fill of the Yangtze delta, China by using anisotropy of magnetic susceptibility data. Mar Geol, 2001, 176: $175-189$

27 Veloso E E, Anma R, Oba T, et al. Paleocurrent patterns of the sedimentary sequence of the Taitao ophiolite constrained by anisotropy of magnetic susceptibility and paleomagnetic analyses. Sediment Geol, 2007, 201: 446-460
28 Tarling D H, Hrouda F. The Magnetic Anisotropy of Rocks. London: Chapman \& Hall, UK, 1993

29 Manley P, Caress D. Mudwaves on the Gardar Sediment Drift, NE Atlantic. Paleoceanography, 1994, 9: 973-988

30 Kanamatsu T, Ohno M, Acton G, et al. Rock magnetic properties of the Gardar Drift sedimentary sequence, Site IODPU1314, North Atlantic: Implication for bottom current change through the midPleistocene. Mar Geol, 2009, 265: 31-39

31 Liu J P. Post-glacial sedimentation on a river-dominated epicontinental shelf: The Yellow Sea example. Dissertation for the Doctoral Degree. VA: The College of William and Mary, USA, 2011, 151

32 Senjyu T, Shin H, Yoon J, et al. Deep flow field in the Japan/East Sea as deduced from direct current measurements. Deep-Sea Research II, 2005, 52: 1726-1741

Open Access This article is distributed under the terms of the Creative Commons Attribution License which permits any use, distribution, and reproduction in any medium, provided the original author(s) and source are credited. 